Keywords: sunitinib; therapeutic drug monitoring; personalised medicine; kinase and phosphatase inhibitors; pharmacokinetics and pharmacodynamics; biodistribution/toxicology

\title{
Pharmacokinetically guided sunitinib dosing: a feasibility study in patients with advanced solid tumours
}

\begin{abstract}
N A G Lankheet ${ }^{1,6}$, J S L Kloth ${ }^{2,6}$, C G M Gadellaa-van Hooijdonk ${ }^{3,4,6}$, G A Cirkel ${ }^{3,4}$, R H J Mathijssen ${ }^{2,4}$, M P J K Lolkema ${ }^{3,4}$, J H M Schellens ${ }^{4,5}$, E E Voest ${ }^{3,4}$, S Sleijfer ${ }^{2,4}$, M J A de Jonge ${ }^{2,4}$, J B A G Haanen ${ }^{5}$, J H Beijnen ${ }^{1}$, A D R Huitema ${ }^{1}$ and N Steeghs ${ }^{\star}, 4,5$

${ }^{1}$ Department of Pharmacy and Pharmacology, Slotervaart Hospital, Louwesweg 6, 1066 EC Amsterdam, The Netherlands; ${ }^{2}$ Department of Medical Oncology, Erasmus MC Cancer Institute, Groene Hilledijk 301, 3075 EA Rotterdam, The Netherlands; ${ }^{3}$ Department of Medical Oncology, University Medical Center Utrecht, Heidelberglaan 100, 3584 CX Utrecht, The Netherlands; ${ }^{4}$ Center for Personalised Cancer Treatment, Heidelberglaan 100, 3584 CX Utrecht, The Netherlands and ${ }^{5}$ Department of Medical Oncology and Clinical Pharmacology, The Netherlands Cancer Institute-Antoni van Leeuwenhoek, Plesmanlaan 12, 1066 CX Amsterdam, The Netherlands
\end{abstract}

Background: Plasma exposure of sunitinib shows large inter-individual variation. Therefore, a pharmacokinetic (PK) study was performed to determine safety and feasibility of sunitinib dosing based on PK levels.

Methods: Patients were treated with sunitinib $37.5 \mathrm{mg}$ once daily. At days 15 and 29 of treatment, plasma trough levels of sunitinib and $\mathrm{N}$-desethyl sunitinib were measured. If the total trough level (TTL) was $<50 \mathrm{ng} \mathrm{ml}^{-1}$ and the patient did not show any grade $\geqslant 3$ toxicity, the daily sunitinib dose was increased by $12.5 \mathrm{mg}$. If the patient suffered from grade $\geqslant 3$ toxicity, the sunitinib dose was lowered by $12.5 \mathrm{mg}$.

Results: Twenty-nine out of 43 patients were evaluable for PK assessments. Grade $\geqslant 3$ adverse events were experienced in seven patients (24\%) at the starting dose and in nine patients (31\%) after dose escalation. TTLs were below target in 15 patients (52\%) at the starting dose. Of these, five patients (17\%) reached target TTL after dose escalation without additional toxicity.

Conclusions: In a third of the patients that were below target TTL at standard dose, the sunitinib dose could be increased without additional toxicities. This could be the basis for future studies and the implementation of a PK-guided dosing strategy in clinical practice.

Sunitinib (Sutent) has proven its efficacy as single agent in several solid tumour types and is approved for use in advanced renal cell cancer (RCC), imatinib-resistant or -intolerant gastrointestinal stromal tumours (GISTs) and pancreatic neuroendocrine tumours (pNET) (Demetri et al, 2006; Motzer et al, 2006; Raymond et al, 2011). Recent findings demonstrated a positive dose-efficacy relationship for sunitinib treatment (Houk et al, 2010). As deduced from pharmacokinetic/pharmacodynamic preclinical data, target total plasma concentrations of sunitinib plus active metabolite ( $\mathrm{N}$-desethyl sunitinib) are in the range of 50-100 $\mathrm{ng} \mathrm{ml}^{-1}$ (Abrams et al, 2003a, b; Mendel et al, 2003; Murray et al, 2003; Faivre et al, 2006). In line with these preclinical data, total trough levels (TTLs) $<50 \mathrm{ng} \mathrm{ml}^{-1}$ have been associated with decreased therapeutic efficacy in patients compared with patients with TTL above this level (Faivre et al, 2006). It is therefore hypothesised that for optimal sunitinib therapy a TTL of $>50 \mathrm{ng} \mathrm{ml}^{-1}$ should be

\footnotetext{
*Correspondence: Dr N Steeghs; E-mail: n.steeghs@nki.nl
}

${ }^{6}$ These authors contributed equally to this work.

Received 6 November 2013; revised 7 February 2014; accepted 17 March 2014; published online 15 April 2014 
reached in each individual patient. However, sunitinib exposure shows considerable variation due to patient non-compliance (e.g., due to drug-related toxicity), drug interactions with co-medication, variability in oral drug availability and many other factors (Klumpen et al, 2011). Despite this considerable inter-patient variability in systemic exposure, sunitinib is currently prescribed at a fixed dose. Given the narrow therapeutic index, the large interindividual variability in systemic exposure, and the positive exposure-efficacy relationship, there is a strong rationale for pharmacokinetically (PK) guided dosing also known as therapeutic drug monitoring (TDM) of sunitinib (de Jonge et al, 2005; Faivre et al, 2006; Houk et al, 2010). Such an approach could contribute to a tailor-made sunitinib treatment with improved therapeutic efficacy and decreased risk for toxicity (Beumer, 2013).

Thus far, no prospective clinical trials investigating the safety and efficacy of PK-guided dosing for sunitinib therapy have been performed. Hence, the ultimate proof that reaching target trough concentrations increases treatment efficacy remains to be awaited. As a first step towards individualised PK-based dosing, we investigated the safety and feasibility of PK-guided sunitinib dosing in a pilot study by measuring sunitinib trough levels. The main purpose of the study was to assess whether PK-guided dosing could be performed without causing additional toxicities. Establishing a feasible and safe PK-guided dosing strategy could provide a rationale for a large prospective clinical trial.

\section{MATERIALS AND METHODS}

Patient population. This multicenter prospective pilot trial (NCT01286896) was initiated in 2011 and was performed in three medical centres in the Netherlands. Eligible patients were patients with histologically or cytologically confirmed advanced tumours for which sunitinib was considered standard therapy or patients with advanced or metastatic tumours for whom no standard therapy was available.

Other inclusion criteria included age $\geqslant 18$ years; an Eastern Cooperative Oncology Group performance status $\leqslant 1$; measurable or evaluable disease according to Response Evaluation Criteria Solid Tumours 1.1 criteria; estimated life expectancy $>12$ weeks; adequate haematologic, hepatic and renal function; no cardiac instability within the previous 6 months. Additionally, patients should be able and willing to undergo blood sampling, and patients should be able to swallow oral medication.

The protocol was approved by local independent ethics committees, and the study was conducted in accordance with the Declaration of Helsinki. All patients received information regarding the purpose and conduct of this study and provided written informed consent.

Study design. Eligible patients started treatment at a dose level of $37.5 \mathrm{mg}$ sunitinib once daily continuously. At day 15 of sunitinib treatment, TTLs of sunitinib plus $\mathrm{N}$-desethyl sunitinib were measured. If the TTL was $<50 \mathrm{ng} \mathrm{ml}^{-1}$ and the patient did not experience any grade $\geqslant 3$ toxicity (CTCAE 4.02), the daily sunitinib dose was increased by $12.5 \mathrm{mg}$ at day 22. At day 29 , 7 days after the first dose adjustment, the second TTL was measured. If indicated, a second dose adjustment based on TTL and/or toxicity was performed at day 36 , as described before. After 8 weeks a final TTL evaluation was performed. No further dose increments were allowed.

If the patient suffered from grade $\geqslant 3$ toxicity or intolerable grade 2 toxicity despite supportive care at any moment during the study, the sunitinib treatment was interrupted until adequate recovery (CTC grade $<2$ ) was achieved. Subsequently, sunitinib treatment was resumed at the next lowest dose level. Sunitinib dose levels allowed within this study were $12.5,25,37.5,50$ and $62.5 \mathrm{mg}$ QD. Patients experiencing grade $>2$ toxicity with sunitinib $12.5 \mathrm{mg}$ once daily discontinued the treatment and went off-study. No dose escalations were allowed after a previous dose reduction for toxicity. Treatment was continued until progressive disease, until patient refusal or until adverse events that required discontinuation of therapy were observed.

Pharmacokinetic analyses. Samples for pharmacokinetics (PK) were collected at day $15 \pm 1$, day $29 \pm 1$ and after 8 weeks (day $57 \pm 1$ ) of sunitinib treatment. EDTA blood samples were collected and, thereafter, directly sent to the laboratory by ordinary mail at ambient temperature. After receipt of the samples, within $36 \mathrm{~h}$ after blood collection, plasma was harvested and stored at $-20{ }^{\circ} \mathrm{C}$ until analysis.

Trough levels of sunitinib and $\mathrm{N}$-desethyl sunitinibin plasma were measured by LC-MS/MS as described before (Lankheet et al, 2013). Total trough levels were determined by calculating the sum of sunitinib and $\mathrm{N}$-desethyl sunitinib plasma levels and were reported to the treating physician within 1 week after blood collection. Patients were evaluable for pharmacokinetic analyses if they had undergone all three PK blood samplings.

Safety assessments. Adverse events (AE), serious adverse events (SAE) and their relationship with study medication were assessed throughout the study. The incidence and severity of AEs were evaluated and graded using the National Cancer Institute Common Toxicity Criteria for Adverse Events version 4.02 (CTCAE 4.02). Patients who received at least one dose of the study treatment were included in the safety evaluation.

Statistical analysis. The number of patients recruited was based on the number estimated to be required to evaluate at least eight patients for toxicity after PK-guided dose escalation. It was expected that $45 \%$ of patients would experience clinically relevant toxicity at the starting dose of $37.5 \mathrm{mg}$ once daily (van der Veldt et al, 2008; Escudier et al, 2009; George et al, 2009; Novello et al, 2009; van Erp et al, 2009). In addition, it was expected that $~ 50 \%$ of the patients without toxicity (55\%) would have TTL $\geqslant 50 \mathrm{ng} \mathrm{ml}^{-1}$ (George et al, 2009; Novello et al, 2009). In both occasions, patients were not eligible for dose escalation. Thus, to be able to evaluate at least eight patients after dose escalation, it was necessary to include about four times as many patients (at least 30 patients).

Descriptive statistics were used to summarise the patient characteristics, toxicity data, response data and sunitinib TTLs.

\section{RESULTS}

Patient population. From April 2011 until June 2012, 43 patients with a variety of advanced solid tumours were enrolled (18 patients at the Netherlands Cancer Institute-Antoni van Leeuwenhoek Amsterdam, 15 patients at the University Medical Center Utrecht and 10 patients at the Erasmus MC Cancer Institute Rotterdam). Forty-two patients received at least one dose of sunitinib and were evaluable for toxicity assessments. Twenty-nine patients completed all three pharmacokinetic blood samples and were therefore evaluable for pharmacokinetic assessments (see Figure 1 for CONSORT diagram). In total, 14 out of 29 patients were evaluable for toxicity assessment after PK-guided dose escalation. At the time of the database lock (August 2012), four patients (9.5\%) were still on sunitinib therapy. Demographical and clinical characteristics for all patients are provided in Table 1.

Target trough levels. After 14 days of sunitinib treatment, the median TTL was $49.5 \mathrm{ng} \mathrm{ml}^{-1}$ (IQR 41.8-64.0) (see Table 2). Considerable inter-patient variability of TTLs was observed at the starting dose with a coefficient of variation (CV\%) of $32.1 \%$. 


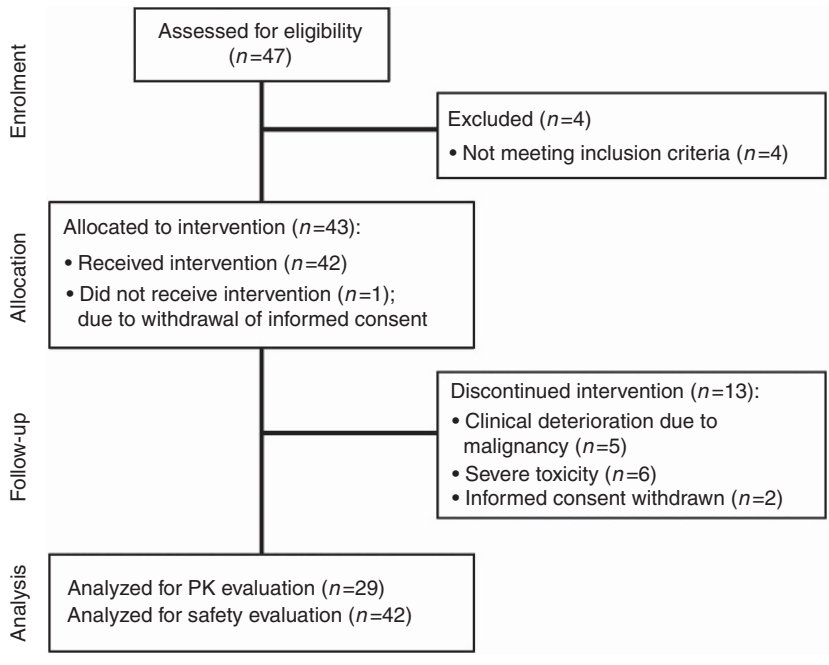

Figure 1. Patient flow diagram.

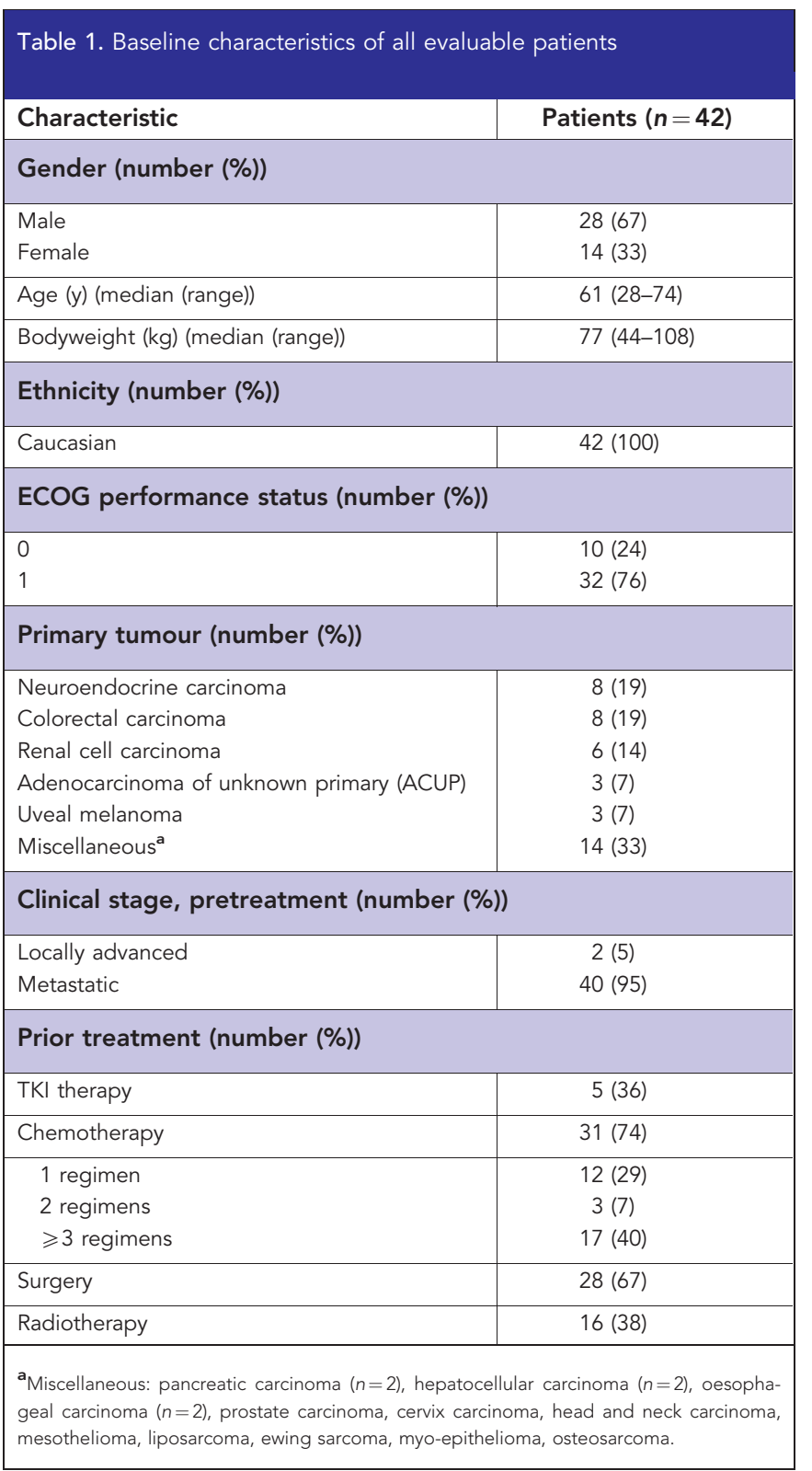

Moreover, 15 out of 29 patients (52\%) did not reach the target TTL of $50 \mathrm{ng} \mathrm{ml}^{-1}$ at the starting dose of $37.5 \mathrm{mg}$ per day. Therefore, dose escalations to $50 \mathrm{mg}$ per day were indicated in 15 patients. However, in one patient it was not possible to increase the sunitinib dose due to haematological toxicity, and therefore dose escalation was performed in 14 patients. At the second PK evaluation (day 29), the median TTL was increased to $57.6 \mathrm{ng} \mathrm{ml}^{-1}$ (IQR 48.3-61.9) with an inter-patient variability of $35.2 \%$ for the entire population of 29 patients. The 14 patients that had undergone dose escalation after day-15 PK measurement (median TTL $42.0 \mathrm{ng} \mathrm{ml}^{-1}$ (IQR 36.3-47.3)) reached median TTL of $51.3 \mathrm{ng} \mathrm{ml}^{-1}$ (IQR 44.7-58.7) at day 29. In two patients dose escalation at day 15 resulted in reduced TTL at day 29. Moreover, 19 out of 29 patients (66\%) reached the target TTL. Of the 10 patients below the target level, the sunitinib dose was increased to $62.5 \mathrm{mg}$ per day in 3 patients and dose escalations were not possible due to toxicity in 7 patients. At the final PK evaluation (day 57), the median TTL was reduced to $51.8 \mathrm{ng} \mathrm{ml}^{-1}$ (40.3-63.7) with an inter-patient variability of $45 \%$ and 15 patients (52\%) reached the target TTL. Six patients in Group 2 showed a decrease in TTL throughout the study without dose adjustments. In two cases this resulted in TTL below the target TTL at day 57. In Figure 2, the measured TTLs of individual patients at days 15, 29 and 57 are presented.

PK-guided dosing. Based on TTL reached at day 15, two patient groups were distinguished: Group 1, which consisted of patients who did not reach target TTL and Group 2, which consisted of patients who reached target TTL. Based on toxicity in the first 8 weeks of treatment, these groups could be subdivided further into four patient subgroups with different results of the PK guided dosing strategy. The defined groups were as follows: Group 1a patients with TTL $<50 \mathrm{ng} \mathrm{ml}^{-1}$ at day 15 and no relevant toxicity $(n=5 ; 17 \%)$, Group $1 \mathrm{~b}$ patients with TTL $<50 \mathrm{ng} \mathrm{ml}^{-1}$ at day 15 with relevant toxicity $(n=10 ; 34 \%)$, Group 2 a patients with $\mathrm{TTL}>50 \mathrm{ng} \mathrm{ml}^{-1}$ at day 15 and no relevant toxicity $(n=8 ; 28 \%)$, Group $2 \mathrm{~b}$ patients with TTL $>50 \mathrm{ng} \mathrm{ml}^{-1}$ at day 15 with relevant toxicity $(n=6 ; 21 \%)$. As shown in Table 2 , the five patients $(17 \%)$ who did not reach target TTL at day 15 and had PK-guided dose elevations without relevant toxicity tolerated treatment with $47 \%$ higher mean daily dose compared with standard therapy. After 8 weeks of treatment the distribution of daily sunitinib doses in the study population was as follows: 2 patients using $62.5 \mathrm{mg}$, 4 patients using $50 \mathrm{mg}, 15$ patients using $37.5 \mathrm{mg}$ and 8 patients using $25 \mathrm{mg}$. Presumably without PK-guided dosing the result would have been 21 patients on $37.5 \mathrm{mg}, 8$ on $25 \mathrm{mg}$, and therefore a possible underdosing in 6 of $29(21 \%)$ of patients.

In Figure 3, an overview of all dose adjustments and TTLs is shown per individual patient within the 8 -week study period.

Treatment toxicity. The most frequently occurring treatment related adverse events are listed in Table 3 . Grade $\geqslant 3$ adverse events were observed in 29 patients $(69 \%)$. The main grade $\geqslant 3$ adverse events attributed to study treatment included hypertension (14\%), fatigue (12\%), anaemia (12\%), thrombocytopenia (12\%) and hand-foot syndrome (HFS) (10\%). Common grade 1 or 2 nonhaematologic treatment-related toxicities were fatigue $(60 \%)$, nausea (50\%), dysgeusia (55\%), oral mucositis (52\%), diarrhoea (40\%), HFS (33\%) and vomiting (29\%).

Six patients discontinued sunitinib treatment (at the standard dose of $37.5 \mathrm{mg}$ per day) due to adverse events before the final PK evaluation at day 57; five of these discontinuations were considered treatment-related and included fatal cardiac failure $(n=1$, grade 5 ), fatigue, increased blood bilirubin, nausea (all $n=1$, grade 3 ) and fatigue $(n=1$, grade 2$)$. Dose reductions of sunitinib due to treatment-related adverse events during the PK evaluation period were performed in 16 patients (Group $1 b+2 b$ ). Moreover, nine of these patients (56\%) (Group 1b) who had an initial TTL-guided 
Table 2. Therapy outcomes regarding reached total trough level (TTL), dose and target $T T L$, stratified by patient group

\begin{tabular}{|c|c|c|c|c|c|}
\hline Outcome & $\begin{array}{c}\text { Group 1a } \\
\text { TTL }<50 \\
\text { No severe TOX } \\
(n=5)\end{array}$ & $\begin{array}{c}\text { Group 1b } \\
\text { TTL }<50 \\
\text { Severe TOX } \\
(n=10)\end{array}$ & $\begin{array}{c}\text { Group } 2 \mathrm{a} \\
\text { TTL } \geqslant 50 \\
\text { No severe TOX } \\
(n=8)\end{array}$ & $\begin{array}{c}\text { Group } 2 b \\
\text { TTL } \geqslant 50 \\
\text { Severe TOX } \\
(n=6)\end{array}$ & $\begin{array}{c}\text { Total } \\
(n=29)\end{array}$ \\
\hline \multicolumn{6}{|c|}{ TTL (ng ml ${ }^{-1}$ ) (median (IQR)) } \\
\hline $\begin{array}{l}\text { Day } 15 \\
\text { Day } 29 \\
\text { Day } 57\end{array}$ & $\begin{array}{l}44.0(41.8-48.8) \\
51.8(45.6-61.5) \\
63.9(56.2-78.3)\end{array}$ & $\begin{array}{l}39.1(30.1-43.0) \\
50.2(43.3-56.3) \\
39.6(31.1-48.2)\end{array}$ & $\begin{array}{l}65.5(56.8-67.9) \\
61.4(58.7-79.3) \\
61.9(55.0-69.6)\end{array}$ & $\begin{array}{l}62.2(56.0-64.7) \\
53.1(40.1-65.8) \\
46.4(37.5-53.6)\end{array}$ & $\begin{array}{c}49.5(41.8-64.0) \\
57.6(48.3-61.9) \\
51.8(40.3-63.7)\end{array}$ \\
\hline
\end{tabular}

Dose (mg) (mean (s.d.))

\begin{tabular}{|l|l|l|l|l|l}
\hline Day 29 & $50.0(-)$ & $47.5(7.9)$ & $37.5(-)$ & $33.3(6.5)$ \\
Day 57 & $55.0(6.8)$ & $35.0(5.3)$ & $37.5(-)$ & $25.0(-)$ \\
\hline
\end{tabular}

Patients on target TTL (number (\%))

\begin{tabular}{|l|l|l|l|l|}
\hline Day 15 & $0(0)$ & $0(0)$ & $8(100)$ & $14(48)$ \\
Day 29 & $3(60)$ & $5(50)$ & $8(100)$ & $3(100)$ \\
Day 57 & $5(100)$ & $1(10)$ & $6(75)$ & $3(50)$ \\
\hline
\end{tabular}

Abbreviations: $I Q R=$ interquartile range; s.d. $=$ standard deviation; TOX = toxicity; TTL = total trough level. Patients were stratified by TTL measured at day 15 and toxicity within 8 weeks of treatment. Patients with $T T L<50 \mathrm{ng} \mathrm{ml}^{-1}$ at day 15 are in group 1. Patients with $T \mathrm{TL} \geqslant 50 \mathrm{ng} \mathrm{ml}^{-1}$ are in group 2 . In addition, subgroups are formed by patients without severe toxicity within 8 weeks of treatment (Groups 1a and 2a) and patients suffering from severe toxicity within 8 weeks (Groups $1 \mathrm{~b}$ and 2b).

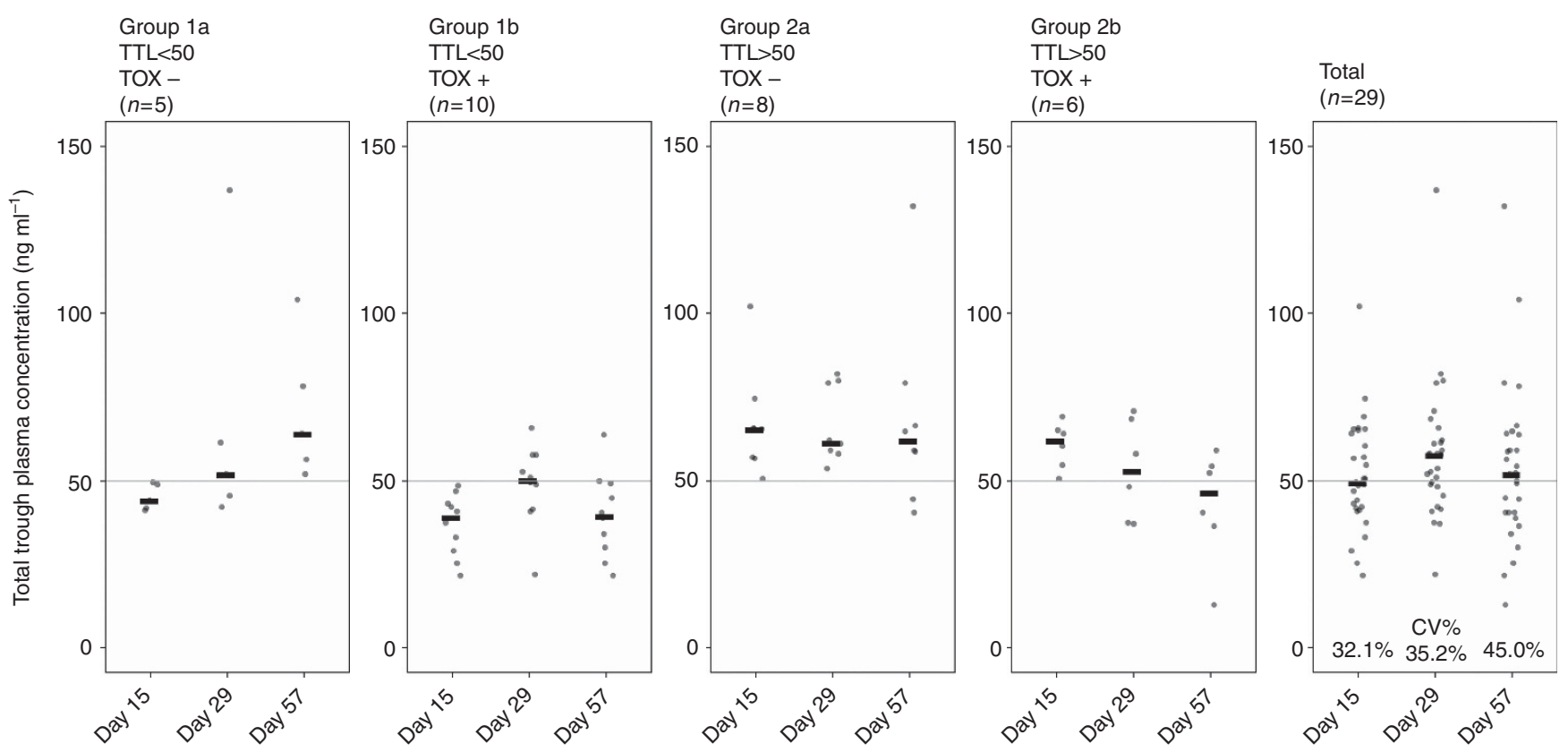

Figure 2. Total trough levels measured at days 15, 29 and 57 of sunitinib treatment of all patients who were evaluable for PK evaluation, stratified by patient group. The black bars represent the median TTL.

dose increase did not tolerate this higher dose level, as shown in Figure 3. In addition, five patients discontinued sunitinib treatment due to toxicity after the PK evaluation period; two of these discontinuations were considered treatment related and included a combination of anaemia and thrombocytopenia $(n=2$, grade 3$)$.

The main purpose of the study was to assess whether PK-guided dosing could be performed without causing additional toxicities. Therefore, the occurrence of toxicities in the patients who required dose escalations (Group 1) was compared with patients who did not need dose interventions based on PK and remained at the standard dose (Group 2). In all patient groups, the frequency of grade $\leqslant 2$ toxicity was similar. TTLs above the target level at day 15 of therapy did not correlate to frequency of severe toxicity (grade $\geqslant 3$ ). In Group 1, 10 out of 15 patients $(67 \%)$ experienced severe toxicities and in Group 2 with TTL $>50 \mathrm{ng} \mathrm{ml}^{-1}, 6$ out of 14 patients (43\%) experienced severe toxicity.

\section{DISCUSSION}

In this pilot study, the safety and feasibility of PK-guided sunitinib dosing was investigated. At the standard dose of $37.5 \mathrm{mg}, 52 \%$ of patients did not reach target TTLs of sunitinib after 14 days of 

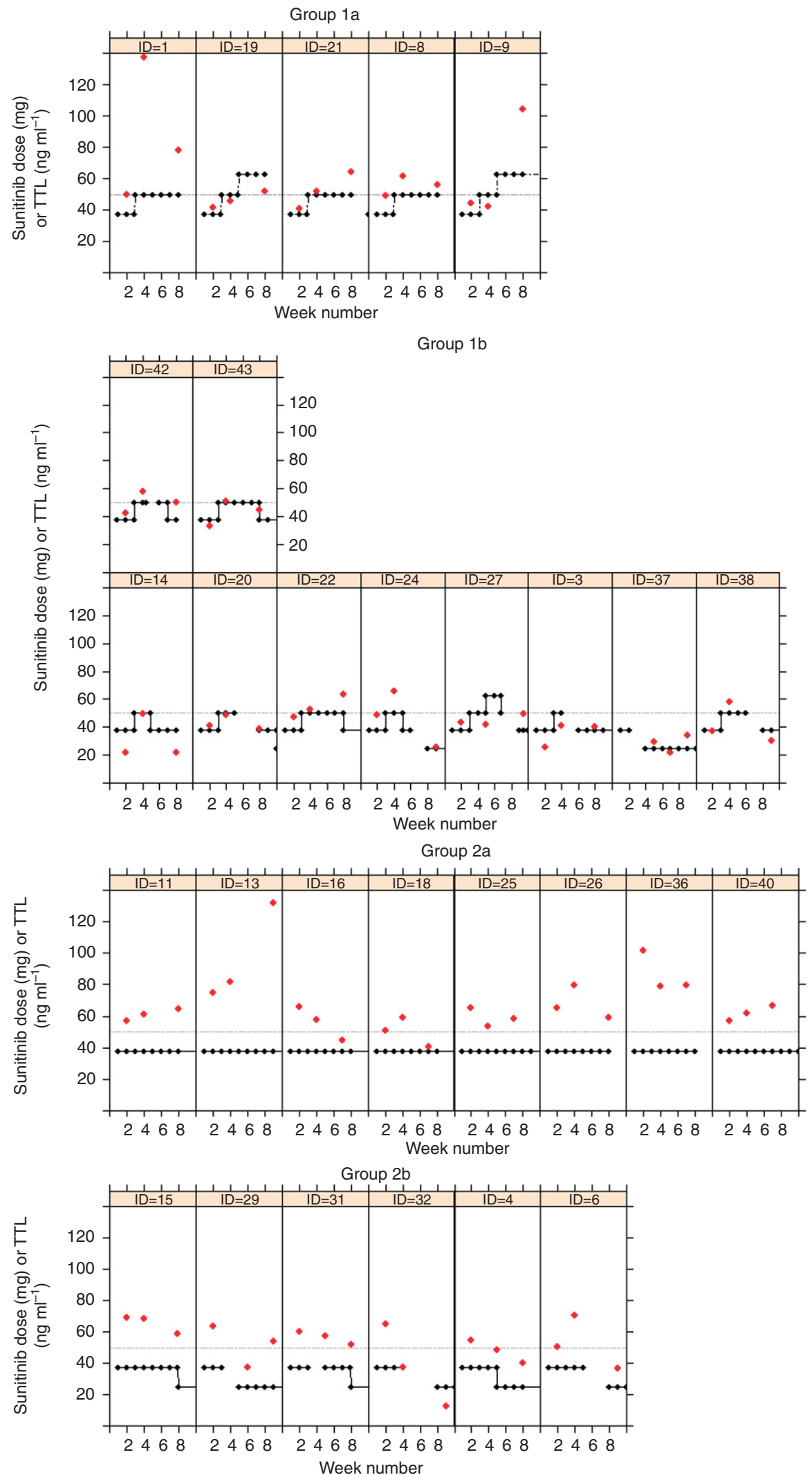

Figure 3. Course of sunitinib dose levels and TTLs during the first 8 weeks of treatment of all individual patients who were evaluable for PK evaluation, stratified by patient group. On the $x$ axis is the week number, on the $y$ axis both sunitinib dose level and TTLs are presented. Red dots represent TTLs. Black squares represent dose levels. The dotted line represents the target TTL $\left(50 \mathrm{ng} \mathrm{ml}^{-1}\right)$. Group $1 \mathrm{a}$ : patients with TTL $<50 \mathrm{ng} \mathrm{ml}^{-1}$ at day 15 and without toxicity; Group $1 \mathrm{~b}$ : patients with TTL $<50 \mathrm{ng} \mathrm{ml}^{-1}$ at day 15 and with toxicity; Group 2a: patients with TTL $>50 \mathrm{ng} \mathrm{ml}^{-1}$ at day 15 and without toxicity; Group $2 \mathrm{~b}$ : patients with $\mathrm{TTL}>50 \mathrm{ng} \mathrm{ml}^{-1}$ at day 15 and with toxicity. 


\begin{tabular}{|c|c|c|c|c|c|c|c|c|c|c|c|c|c|c|c|c|c|c|c|c|c|c|c|c|c|c|}
\hline \multirow[b]{3}{*}{$\begin{array}{l}\text { Adverse } \\
\text { event }\end{array}$} & \multicolumn{2}{|c|}{ Discontinued } & \multicolumn{4}{|c|}{ Group 1} & \multicolumn{4}{|c|}{ Group 2} & \multirow{2}{*}{\multicolumn{2}{|c|}{$\begin{array}{l}\text { Total } \\
(n=42)\end{array}$}} & \multirow{2}{*}{\multicolumn{2}{|c|}{$\begin{array}{c}\text { Discontinued } \\
(n=13)\end{array}$}} & \multicolumn{4}{|c|}{ Group 1} & \multicolumn{4}{|c|}{ Group 2} & \multirow{2}{*}{\multicolumn{2}{|c|}{$\begin{array}{l}\text { Total } \\
(n=42)\end{array}$}} & \multirow{2}{*}{\multicolumn{2}{|c|}{$\begin{array}{l}\text { Total } \\
(n=42)\end{array}$}} \\
\hline & \multicolumn{2}{|c|}{$(n=13)$} & \multicolumn{2}{|c|}{$\begin{array}{c}\text { Group 1a } \\
(n=5)\end{array}$} & \multicolumn{2}{|c|}{$\begin{array}{c}\text { Group 1b } \\
(n=10)\end{array}$} & \multicolumn{2}{|c|}{$\begin{array}{c}\text { Group 2a } \\
n=(8)\end{array}$} & \multicolumn{2}{|c|}{$\begin{array}{c}\text { Group 2b } \\
n=(6)\end{array}$} & & & & & \multicolumn{2}{|c|}{$\begin{array}{c}\text { Group 1a } \\
(n=5)\end{array}$} & \multicolumn{2}{|c|}{$\begin{array}{c}\text { Group 1b } \\
(n=10)\end{array}$} & \multicolumn{2}{|c|}{$\begin{array}{c}\text { Group 2a } \\
(n=8)\end{array}$} & \multicolumn{2}{|c|}{$\begin{array}{c}\text { Group 2b } \\
(n=6)\end{array}$} & & & & \\
\hline & $n$ & $\%$ & $n$ & $\%$ & $n$ & $\%$ & $n$ & $\%$ & $n$ & $\%$ & $n$ & $\%$ & $n$ & $\%$ & $n$ & $\%$ & $n$ & $\%$ & $n$ & $\%$ & $n$ & $\%$ & $n$ & $\%$ & $n$ & $\%$ \\
\hline
\end{tabular}

Treatment-related non-haematological adverse events (ocurring in $\geqslant 10 \%$ of patients)

\begin{tabular}{|c|c|c|c|c|c|c|c|c|c|c|c|c|c|c|c|c|c|c|c|c|c|c|c|c|c|c|}
\hline Fatigue & 7 & 54 & 4 & 80 & 6 & 60 & 5 & 63 & 3 & 50 & 25 & 60 & 2 & 15 & 0 & 0 & 2 & 20 & 0 & 0 & 1 & 17 & 5 & 12 & 30 & 71 \\
\hline Nausea & 6 & 46 & 3 & 60 & 4 & 40 & 4 & 50 & 4 & 67 & 21 & 50 & 2 & 15 & 0 & 0 & 0 & 0 & 1 & 13 & 0 & 0 & 3 & 7 & 24 & 57 \\
\hline Dysgeusia & 6 & 46 & 4 & 80 & 5 & 50 & 4 & 50 & 4 & 67 & 23 & 55 & 0 & 0 & 0 & 0 & 0 & 0 & 0 & 0 & 0 & 0 & 0 & 0 & 23 & 55 \\
\hline Oral mucositis & 3 & 23 & 2 & 40 & 8 & 80 & 5 & 63 & 4 & 67 & 22 & 52 & 0 & 0 & 0 & 0 & 0 & 0 & 0 & 0 & 1 & 17 & 1 & 2 & 23 & 55 \\
\hline Diarrhoea & 3 & 23 & 3 & 60 & 3 & 30 & 4 & 50 & 4 & 67 & 17 & 40 & 0 & 0 & 1 & 20 & 1 & 10 & 1 & 13 & 0 & 0 & 3 & 7 & 20 & 48 \\
\hline $\begin{array}{l}\text { Hand-foot } \\
\text { syndrome }\end{array}$ & 2 & 15 & 3 & 60 & 5 & 50 & 2 & 25 & 2 & 33 & 14 & 33 & 0 & 0 & 0 & 0 & 3 & 30 & 1 & 13 & 0 & 0 & 4 & 10 & 18 & 43 \\
\hline Vomiting & 4 & 31 & 5 & 100 & 2 & 20 & 1 & 13 & 0 & 0 & 12 & 29 & 0 & 0 & 0 & 0 & 0 & 0 & 1 & 13 & 0 & 0 & 1 & 2 & 13 & 31 \\
\hline Hypertension & 1 & 8 & 1 & 20 & 0 & 0 & 3 & 38 & 0 & 0 & 5 & 12 & 2 & 15 & 2 & 40 & 0 & 0 & 1 & 13 & 1 & 17 & 6 & 14 & 11 & 26 \\
\hline Anorexia & 2 & 15 & 0 & 0 & 2 & 20 & 0 & 0 & 2 & 33 & 6 & 14 & 1 & 8 & 0 & 0 & 0 & 0 & 0 & 0 & 0 & 0 & 1 & 2 & 7 & 17 \\
\hline Dry skin & 2 & 15 & 2 & 40 & 2 & 20 & 0 & 0 & 2 & 33 & 8 & 19 & 0 & 0 & 0 & 0 & 0 & 0 & 0 & 0 & 0 & 0 & 0 & 0 & 8 & 19 \\
\hline Rash & 0 & 0 & 0 & 0 & 3 & 30 & 4 & 50 & 1 & 17 & 8 & 19 & 0 & 0 & 0 & 0 & 0 & 0 & 0 & 0 & 0 & 0 & 0 & 0 & 8 & 19 \\
\hline Constipation & 1 & 8 & 1 & 20 & 3 & 30 & 1 & 13 & 0 & 0 & 6 & 14 & 1 & 8 & 0 & 0 & 0 & 0 & 0 & 0 & 0 & 0 & 1 & 2 & 7 & 17 \\
\hline Epistaxis & 2 & 15 & 0 & 0 & 2 & 20 & 2 & 25 & 0 & 0 & 6 & 14 & 0 & 0 & 0 & 0 & 0 & 0 & 0 & 0 & 1 & 17 & 1 & 2 & 7 & 17 \\
\hline Dyspnoea & 2 & 15 & 0 & 0 & 2 & 20 & 1 & 13 & 0 & 0 & 5 & 12 & 1 & 8 & 0 & 0 & 0 & 0 & 0 & 0 & 0 & 0 & 1 & 2 & 6 & 14 \\
\hline $\begin{array}{l}\text { Skin yellow } \\
\text { discoloration }\end{array}$ & 2 & 15 & 0 & 0 & 1 & 10 & 2 & 25 & 1 & 17 & 6 & 14 & 0 & 0 & 0 & 0 & 0 & 0 & 0 & 0 & 0 & 0 & 0 & 0 & 6 & 14 \\
\hline Dyspepsia & 0 & 0 & 2 & 40 & 1 & 10 & 1 & 13 & 1 & 17 & 5 & 12 & 0 & 0 & 0 & 0 & 0 & 0 & 0 & 0 & 0 & 0 & 0 & 0 & 5 & 12 \\
\hline $\begin{array}{l}\text { Hair } \\
\text { depigmentation }\end{array}$ & 0 & 0 & 2 & 40 & 1 & 10 & 2 & 25 & 0 & 0 & 5 & 12 & 0 & 0 & 0 & 0 & 0 & 0 & 0 & 0 & 0 & 0 & 0 & 0 & 5 & 12 \\
\hline Oral pain & 1 & 8 & 0 & 0 & 0 & 0 & 4 & 50 & 0 & 0 & 5 & 12 & 0 & 0 & 0 & 0 & 0 & 0 & 0 & 0 & 0 & 0 & 0 & 0 & 5 & 12 \\
\hline $\begin{array}{l}\text { Periorbital } \\
\text { oedema }\end{array}$ & 2 & 15 & 0 & 0 & 2 & 20 & 0 & 0 & 1 & 17 & 5 & 12 & 0 & 0 & 0 & 0 & 0 & 0 & 0 & 0 & 0 & 0 & 0 & 0 & 5 & 12 \\
\hline $\begin{array}{l}\text { Periph. } \\
\text { Neuropathy }\end{array}$ & 1 & 8 & 0 & 0 & 2 & 20 & 1 & 13 & 1 & 17 & 5 & 12 & 0 & 0 & 0 & 0 & 0 & 0 & 0 & 0 & 0 & 0 & 0 & 0 & 5 & 12 \\
\hline \multicolumn{27}{|c|}{ Laboratory abnormalities } \\
\hline \multicolumn{27}{|l|}{ Haematology } \\
\hline Anaemia & 1 & 8 & 0 & 0 & 0 & 0 & 0 & 0 & 0 & 0 & 1 & 2 & 1 & 8 & 0 & 0 & 1 & 10 & 1 & 13 & 2 & 33 & 5 & 12 & 6 & 14 \\
\hline $\begin{array}{l}\text { White blood } \\
\text { cells }\end{array}$ & 0 & 0 & 0 & 0 & 0 & 0 & 1 & 13 & 1 & 17 & 2 & 2 & 0 & 0 & 0 & 0 & 1 & 10 & 0 & 0 & 1 & 17 & 2 & 5 & 4 & 10 \\
\hline Neutrophils & 0 & 0 & 1 & 20 & 2 & 20 & 0 & 0 & 3 & 50 & 6 & 14 & 1 & 8 & 1 & 20 & 2 & 20 & 0 & 0 & 1 & 17 & 5 & 12 & 11 & 26 \\
\hline Platelets & 1 & 8 & 1 & 20 & 0 & 0 & 2 & 25 & 0 & 0 & 4 & 10 & 0 & 0 & 0 & 0 & 1 & 10 & 0 & 0 & 2 & 33 & 3 & 7 & 7 & 17 \\
\hline \multicolumn{27}{|l|}{ Clinical chemistry } \\
\hline ALAT & 0 & 0 & 0 & 0 & 1 & 10 & 2 & 25 & 0 & 0 & 3 & 7 & 0 & 0 & 1 & 20 & 0 & 0 & 1 & 13 & 0 & 0 & 2 & 5 & 5 & 12 \\
\hline ASAT & 0 & 0 & 0 & 0 & 0 & 0 & 1 & 13 & 0 & 0 & 1 & 2 & 0 & 0 & 1 & 20 & 1 & 10 & 1 & 13 & 0 & 0 & 3 & 7 & 4 & 10 \\
\hline $\begin{array}{l}\text { Creatinine } \\
\text { increased }\end{array}$ & 0 & 0 & 0 & 0 & 1 & 10 & 1 & 13 & 1 & 17 & 3 & 7 & 1 & 8 & 0 & 0 & 0 & 0 & 0 & 0 & 0 & 0 & 1 & 2 & 4 & 10 \\
\hline \multicolumn{27}{|l|}{ Cardial events } \\
\hline Heart failure & 0 & 0 & 0 & 0 & 0 & 0 & 0 & 0 & 0 & 0 & 0 & 0 & 1 & 8 & 1 & 20 & 0 & 0 & 0 & 0 & 0 & 0 & 2 & 5 & 2 & 5 \\
\hline $\begin{array}{l}\text { Acute } \\
\text { coronairy } \\
\text { syndrome }\end{array}$ & 0 & 0 & 0 & 0 & 0 & 0 & 0 & 0 & 0 & 0 & 0 & 0 & 1 & 8 & 0 & 0 & 0 & 0 & 0 & 0 & 0 & 0 & 1 & 2 & 1 & 2 \\
\hline $\begin{array}{l}\text { Prolonged } \\
\text { QT interval }\end{array}$ & 0 & 0 & 0 & 0 & 0 & 0 & 0 & 0 & 0 & 0 & 0 & 0 & 0 & 0 & 0 & 0 & 0 & 0 & 1 & 13 & 0 & 0 & 1 & 2 & 1 & 2 \\
\hline $\begin{array}{l}\text { Myocardial } \\
\text { infarction }\end{array}$ & 0 & 0 & 0 & 0 & 0 & 0 & 0 & 0 & 0 & 0 & 0 & 0 & 0 & 0 & 0 & 0 & 0 & 0 & 1 & 13 & 0 & 0 & 1 & 2 & 1 & 2 \\
\hline Any toxicity & 13 & 100 & 5 & 100 & 10 & 100 & 8 & 100 & 6 & 100 & & 100 & 7 & 54 & 3 & 60 & 9 & 90 & 5 & 63 & 5 & 83 & 29 & 69 & & 100 \\
\hline
\end{tabular}


sunitinib treatment. Ultimately, 5 out of 29 patients $(17 \%)$ had successful dose escalations with final doses of $50 \mathrm{mg}(n=3)$ and $62.5 \mathrm{mg}(n=2)$, leading to TTLs above the target without causing additional toxicities. This implies that PK-guided sunitinib dose escalations rather than fixed doses can contribute to optimisation of therapy in a part of the patients.

Similar to classical anticancer chemotherapy regimens, it is often reasoned that increasing the dose of an anticancer drug in patients who lack toxicity might increase the likelihood of treatment efficacy (Mita et al, 2011; Gao et al, 2012; Pond et al, 2012; Rini et al, 2013). Fixed dosing may lead to underdosing due to inadequate drug exposure in some patients. Dosing to toxicity might lead to overdosing and unnecessary side effects, as in some patients adequate drug exposure will already be accomplished with a lower dose. This is complex since drug exposure, toxicity and efficacy generally do not show a linear relationship and it is not known whether toxicity is accompanied by adequate exposure. Therefore, therapeutic drug monitoring for the individualisation of dosing of anticancer drugs with a considerable and unpredictable inter-patient variability in pharmacokinetics is gaining popularity. For example, PK-guided dosing has been mentioned for docetaxel leading to a decrease in the inter-patient variability of drug exposure (Engels et al, 2011). However, to our knowledge, the current study is the first in which PK-guided dosing is applied to sunitinib treatment.

The sunitinib starting dose of $37.5 \mathrm{mg}$ (continuously once-daily) was based on previously reported studies investigating a continuous dosing strategy for sunitinib (Escudier et al, 2009; George et al, 2009; Novello et al, 2009). As no safety data were available regarding long-term continuous daily dosing of high-dose sunitinib, the highest dose level was maximised to $62.5 \mathrm{mg}$ per day (Escudier et al, 2009; George et al, 2009; Novello et al, 2009; Motzer et al, 2012).

A limitation of this study is that target TTL have not been established in clinical studies, thus far. The association between sunitinib exposure and efficacy was based on the steady-state area under the concentration-time curve (AUC) (Houk et al, 2010). As both AUC and trough level increase proportionally with dose, these parameters should correlate with each other (EMA, 2007; Faivre et al, 2006). Hence, the target plasma levels used in this study were deduced from preclinical studies (Abrams et al, 2003a, b; Mendel et al, 2003; Murray et al, 2003). Furthermore, our study was performed in a small cohort of patients with a large variety of advanced solid tumours and without a control group. Therefore, it was not possible to investigate the relationship between plasma exposure and treatment efficacy.

In the previously reported studies, mean TTLs were $\sim 40-65 \mathrm{ng} \mathrm{ml}^{-1}$ and inter-patient variability was high with a coefficient of variation (CV) of $>30 \%$ (Escudier et al, 2009; George et al, 2009; Novello et al, 2009; Motzer et al, 2012). Our patient cohort showed comparable results after 14 days of treatment (before any dose change) with median TTL of $49.5 \mathrm{ng} \mathrm{ml}^{-1}$ and an inter-patient variability of $31.2 \%$. When assuming that target TTLs are needed for adequate treatment responses, this means that more than half of the patients were at subtarget levels $\left(<50 \mathrm{ng} \mathrm{ml}^{-1}\right)$ at the standard dose.

Based on the elimination half-life of sunitinib $( \pm 40 \mathrm{~h})$ and $\mathrm{N}$-desethyl sunitinib $( \pm 80 \mathrm{~h})$ it was expected that steady-state concentrations would be reached within 14 days of treatment and that parent and metabolite accumulate 3-4-fold and 7-10-fold, respectively (EMA, 2007). However, no significant drug accumulation was observed after 3 weeks of continuous sunitinib treatment in previous studies (George et al, 2009; Barrios et al, 2012). Additionally, in case of a dose escalation from $37.5 \mathrm{mg}$ to $50 \mathrm{mg}$ (33\% increment) $>90 \%$ of the new steady-state level would already be reached after two half-lifes since the new steady state is close to the former level. Therefore, TTL measurement 7 days after a dose escalation was expected to be adequate. However, in some patients TTLs still tended to increase after 2 weeks of sunitinib treatment even when the dose remained equal. A longer period before collection of the first TTL sample was considered, but this would postpone potential beneficial dose increments. In addition, it was observed that TTLs in two out of eight patients decreased to below the target TTL without a dose reduction after 8 weeks of treatment. It is not known whether this is due to unexplained intra-patient variability, patient non-adherence (despite using diaries and pill counts) or whether sunitinib levels tend to decrease after long term treatment as was shown for imatinib (Eechoute et al, 2012) and sorafenib (Arrondeau et al, 2012; BoudouRouquette et al, 2012). Hence, further insights in TTLs and interpatient pharmacokinetic variability during sunitinib treatment are warranted to allow rational design of future PK-guided dosing studies (Kloth et al, 2013).

The total occurrence of toxicity grade 3 or higher observed in this study was consistent with previously reported studies on continuous daily dosing regimens of sunitinib (Escudier et al, 2009; George et al, 2009; Novello et al, 2009; Motzer et al, 2012). Owing to the small patient number this study was not powered to compare the occurrence of toxicities within the different patient subgroups.

Of all 16 patients who required dose reductions due to toxicity (Group $1 b+2 b), 7$ patients suffered from toxicities at the standard dose and would also have experienced these toxicities if they were treated without the PK-guided dosing strategy. The same goes for one patient in the study who died due to a probable treatmentrelated adverse event (diffuse cardiac ischaemia followed by cardiac failure) at the starting dose of $37.5 \mathrm{mg}$ per day. However, as could be expected, patients did experience additional toxicities after PKguided dose escalations (nine patients). These toxicities were manageable by dose reductions.

As suggested by previous data, it was expected that toxicity was correlated to sunitinib exposure (Houk et al, 2010). However, results indicated that the frequency of severe toxicities (grade $\geqslant 3$ ) was not correlated to TTL at day 15 , as toxicity levels at that timepoint were comparable in the patients with TTL $<50 \mathrm{ng} \mathrm{ml}^{-1}$ (Group 1) and TTL $>50 \mathrm{ng} \mathrm{ml}^{-1}$ (Group 2). Probably toxicity is alsocorrelated to cumulative sunitinib exposure instead of the initial steady state TTL, as was also reported for absolute neutrophil counts by Houk et al (2010).

In addition, the daily sunitinib doses after 8 weeks of treatment in our patient cohort also give insights in a possible added value of a PK-guided dosing strategy. Six patients $(21 \%)$ were treated with sunitinib doses above the standard dose of $37.5 \mathrm{mg}$ per day. These patients would probably be underdosed in a fixed dosing regimen.

There are several benefits of a PK-guided dosing approach for sunitinib. First, one could hypothesise, based on our results and previous work by other groups, that if an effective TTL can not be reached at a dose level with tolerable toxicity in these patients, TTL assessments could substantiate the choice to switch to another more effective therapy. Second, when assuming that TTLs $>50 \mathrm{ng} \mathrm{ml}^{-1}$ are needed for adequate treatment responses, $17 \%$ of patients (the five patients in Group 1a (TTL $<50 \mathrm{ng} \mathrm{ml}^{-1}$ and no toxicity)) benefit from PK-guided dose increases without additional toxicity. Third, compared with a toxicity-based approach, additional toxicities might be avoided, because adequate drug exposure is reached before toxicity occurs. However, efficacy of both approaches have not been studied or compared in great detail sofar.

In the current oncology field we are more and more searching for personalised treatments options for a sometimes small number of patients. With a little effort we can sometimes optimise the treatment options we already have. Individualising dosing of sunitinib based on a simple measurement of plasma concentration is worthwhile to investigate further in order to utilise the scarce 
treatment options available for many tumour types in a most optimal way. Further research is therefore required to investigate the safety and therapeutic efficacy of PK-guided dosing of sunitinib in order to reach a systemic exposure above the target TTL compared with that from a standard fixed dose.

\section{ACKNOWLEDGEMENTS}

This trial was supported by an unconditional research grant from Pfizer Oncology.

\section{CONFLICT OF INTEREST}

The authors declare no conflict of interest.

\section{REFERENCES}

Abrams TJ, Lee LB, Murray LJ, Pryer NK, Cherrington JM (2003a) SU11248 inhibits KIT and platelet-derived growth factor receptor beta in preclinical models of human small cell lung cancer. Mol Cancer Ther 2: 471-478.

Abrams TJ, Murray LJ, Pesenti E, Holway VW, Colombo T, Lee LB, Cherrington JM, Pryer NK (2003b) Preclinical evaluation of the tyrosine kinase inhibitor SU11248 as a single agent and in combination with "standard of care" therapeutic agents for the treatment of breast cancer. Mol Cancer Ther 2: 1011-1021.

Arrondeau J, Mir O, Boudou-Rouquette P, Coriat R, Ropert S, Dumas G, Rodrigues MJ, Rousseau B, Blanchet B, Goldwasser F (2012) Sorafenib exposure decreases over time in patients with hepatocellular carcinoma. Invest New Drugs 30: 2046-2049.

Barrios CH, Hernandez-Barajas D, Brown MP, Lee SH, Fein L, Liu JH, Hariharan S, Martell BA, Yuan J, Bello A, Wang Z, Mundayat R, Rha SY (2012) Phase II trial of continuous once-daily dosing of sunitinib as first-line treatment in patients with metastatic renal cell carcinoma. Cancer 118: 1252-1259.

Beumer JH (2013) Without therapeutic drug monitoring, there is no personalized cancer care. Clin Pharmacol Ther 93: 228-230.

Boudou-Rouquette P, Ropert S, Mir O, Coriat R, Billemont B, Tod M, Cabanes L, Franck N, Blanchet B, Goldwasser F (2012) Variability of sorafenib toxicity and exposure over time: a pharmacokinetic/ pharmacodynamic analysis. Oncologist 17: 1204-1212.

de Jonge ME, Huitema AD, Schellens JH, Rodenhuis S, Beijnen JH (2005) Individualised cancer chemotherapy: strategies and performance of prospective studies on therapeutic drug monitoring with dose adaptation: a review. Clin Pharmacokinet 44: 147-173.

Demetri GD, van Oosterom AT, Garrett CR, Blackstein ME, Shah MH, Verweij J, McArthur G, Judson IR, Heinrich MC, Morgan JA, Desai J, Fletcher CD, George S, Bello CL, Huang X, Baum CM, Casali PG (2006) Efficacy and safety of sunitinib in patients with advanced gastrointestinal stromal tumour after failure of imatinib: a randomised controlled trial. Lancet 368: 1329-1338.

Eechoute K, Fransson MN, Reyners AK, de Jong FA, Sparreboom A, van der Graaf WT, Friberg LE, Schiavon G, Wiemer EA, Verweij J, Loos WJ, Mathijssen RH, De Giorgi U (2012) A long-term prospective population pharmacokinetic study on imatinib plasma concentrations in GIST patients. Clin Cancer Res 18: 5780-5787.

EMA (2007) Sutent: EPAR—scientific discussion. http://www.ema.europa.eu/ docs/en_GB/document_library/EPAR_-_Scientific_Discussion_-_Variation/ human/000687/WC500089487.pdf.

Engels FK, Loos WJ, van der Bol JM, de Bruijn P, Mathijssen RH, Verweij J, Mathot RA (2011) Therapeutic drug monitoring for the individualization of docetaxel dosing: a randomized pharmacokinetic study. Clin Cancer Res 17: 353-362.

Escudier B, Roigas J, Gillessen S, Harmenberg U, Srinivas S, Mulder SF, Fountzilas G, Peschel C, Flodgren P, Maneval EC, Chen I, Vogelzang NJ (2009) Phase II study of sunitinib administered in a continuous once-daily dosing regimen in patients with cytokine-refractory metastatic renal cell carcinoma. J Clin Oncol 27: 4068-4075.
Faivre S, Delbaldo C, Vera K, Robert C, Lozahic S, Lassau N, Bello C, Deprimo S, Brega N, Massimini G, Armand JP, Scigalla P, Raymond E (2006) Safety, pharmacokinetic, and antitumor activity of SU11248, a novel oral multitarget tyrosine kinase inhibitor, in patients with cancer. $J$ Clin Oncol 24: 25-35.

Gao B, Yeap S, Clements A, Balakrishnar B, Wong M, Gurney H (2012) Evidence for therapeutic drug monitoring of targeted anticancer therapies. J Clin Oncol 30: 4017-4025.

George S, Blay JY, Casali PG, Le CA, Stephenson P, Deprimo SE, Harmon CS, Law CN, Morgan JA, Ray-Coquard I, Tassell V, Cohen DP, Demetri GD (2009) Clinical evaluation of continuous daily dosing of sunitinib malate in patients with advanced gastrointestinal stromal tumour after imatinib failure. Eur J Cancer 45: 1959-1968.

Houk BE, Bello CL, Poland B, Rosen LS, Demetri GD, Motzer RJ (2010) Relationship between exposure to sunitinib and efficacy and tolerability endpoints in patients with cancer: results of a pharmacokinetic/ pharmacodynamic meta-analysis. Cancer Chemother Pharmacol 66: 357-371.

Kloth JS, Klumpen HJ, Yu H, Eechoute K, Samer CF, Kam BL, Huitema AD, Daali Y, Zwinderman AH, Balakrishnar B, Bennink RJ, Wong M, Schellens JH, Mathijssen RH, Gurney H (2013) Predictive value of CYP3A and $\mathrm{ABCB} 1$ phenotyping probes for the pharmacokinetics of sunitinib: the clearsun study. Clin Pharmacokinet; e-pub ahead of print 15 November 2013.

Klumpen HJ, Samer CF, Mathijssen RH, Schellens JH, Gurney H (2011) Moving towards dose individualisation of tyrosine kinase inhibitors. Cancer Treat Rev 37: 251-260.

Lankheet NA, Steeghs N, Rosing H, Schellens JH, Beijnen JH, Huitema AD (2013) Quantification of sunitinib and N-desethyl sunitinib in human EDTA plasma by liquid chromatography coupled with electrospray ionization tandem mass spectrometry: validation and application in routine therapeutic drug monitoring. Ther Drug Monit 35: 168-176.

Mendel DB, Laird AD, Xin X, Louie SG, Christensen JG, Li G, Schreck RE, Abrams TJ, Ngai TJ, Lee LB, Murray LJ, Carver J, Chan E, Moss KG, Haznedar JO, Sukbuntherng J, Blake RA, Sun L, Tang C, Miller T, Shirazian S, McMahon G, Cherrington JM (2003) In vivo antitumor activity of SU11248, a novel tyrosine kinase inhibitor targeting vascular endothelial growth factor and platelet-derived growth factor receptors: determination of a pharmacokinetic/pharmacodynamic relationship. Clin Cancer Res 9: 327-337.

Mita AC, Papadopoulos K, de Jonge MJA, Schwartz G, Verweij J, Mita MM, Ricart A, Chu QC, Tolcher AW, Wood L, McCarthy S, Hamilton M, Iwata K, Wacker B, Witt K, Rowinsky EK (2011) Erlotinib 'dosing-to-rash': a phase II intrapatient dose escalation and pharmacologic study of erlotinib in previously treated advanced non-small cell lung cancer. Br J Cancer 105: 938-944.

Motzer RJ, Hutson TE, Olsen MR, Hudes GR, Burke JM, Edenfield WJ, Wilding G, Agarwal N, Thompson JA, Cella D, Bello A, Korytowsky B, Yuan J, Valota O, Martell B, Hariharan S, Figlin RA (2012) Randomized phase II trial of sunitinib on an intermittent versus continuous dosing schedule as first-line therapy for advanced renal cell carcinoma. J Clin Oncol 30: 1371-1377.

Motzer RJ, Michaelson MD, Redman BG, Hudes GR, Wilding G, Figlin RA, Ginsberg MS, Kim ST, Baum CM, DePrimo SE, Li JZ, Bello CL, Theuer CP, George DJ, Rini BI (2006) Activity of SU11248, a multitargeted inhibitor of vascular endothelial growth factor receptor and platelet-derived growth factor receptor, in patients with metastatic renal cell carcinoma. J Clin Oncol 24: 16-24.

Murray LJ, Abrams TJ, Long KR, Ngai TJ, Olson LM, Hong W, Keast PK, Brassard JA, O'Farrell AM, Cherrington JM, Pryer NK (2003) SU11248 inhibits tumor growth and CSF-1R-dependent osteolysis in an experimental breast cancer bone metastasis model. Clin Exp Metastasis 20: $757-766$.

Novello S, Scagliotti GV, Rosell R, Socinski MA, Brahmer J, Atkins J, Pallares C, Burgess R, Tye L, Selaru P, Wang E, Chao R, Govindan R (2009) Phase II study of continuous daily sunitinib dosing in patients with previously treated advanced non-small cell lung cancer. Br J Cancer 101: 1543-1548.

Pond GR, Berry WR, Galsky MD, Wood BA, Leopold L, Sonpavde G (2012) Neutropenia as a potential pharmacodynamic marker for docetaxel-based chemotherapy in men with metastatic castration-resistant prostate cancer. Clin Genitourin Cancer 10: 239-245.

Raymond E, Dahan L, Raoul JL, Bang YJ, Borbath I, Lombard-Bohas C, Valle J, Metrakos P, Smith D, Vinik A, Chen JS, Horsch D, Hammel P, 
Wiedenmann B, Van Cutsem E, Patyna S, Lu DR, Blanckmeister C, Chao R, Ruszniewski P (2011) Sunitinib malate for the treatment of pancreatic neuroendocrine tumors. $N$ Engl J Med 364: 501-513.

Rini BI, Garrett M, Poland B, Dutcher JP, Rixe O, Wilding G, Stadler WM, Pithavala YK, Kim S, Tarazi J, Motzer RJ (2013) Axitinib in metastatic renal cell carcinoma: results of a pharmacokinetic and pharmacodynamic analysis. J Clin Pharmacol 53: 491-504.

van der Veldt AA, Boven E, Helgason HH, van Wouwe M, Berkhof J, de Gast G, Mallo H, Tillier CN, van den Eertwegh AJ, Haanen JB (2008) Predictive factors for severe toxicity of sunitinib in unselected patients with advanced renal cell cancer. Br J Cancer 99: 259-265. van Erp NP, Eechoute K, van der Veldt AA, Haanen JB, Reyners AK, Mathijssen RH, Boven E, van der Straaten T, Baak-Pablo RF, Wessels JA, Guchelaar HJ, Gelderblom H (2009) Pharmacogenetic pathway analysis for determination of sunitinib-induced toxicity. J Clin Oncol 27: 4406-4412.

This work is published under the standard license to publish agreement. After 12 months the work will become freely available and the license terms will switch to a Creative Commons AttributionNonCommercial-Share Alike 3.0 Unported License. 